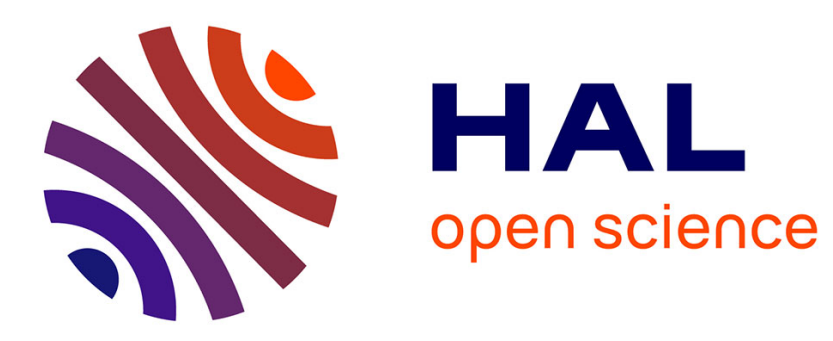

\title{
Increased entropy production in diaphragm muscle of PPAR alpha knockout mice
}

Yves Lecarpentier, X. Krokidis, P. Martin, T. Pineau, Jean-Louis Hébert, J. Quillard, Miguel Cortes-Morichetti, Catherine Coirault

\section{To cite this version:}

Yves Lecarpentier, X. Krokidis, P. Martin, T. Pineau, Jean-Louis Hébert, et al.. Increased entropy production in diaphragm muscle of PPAR alpha knockout mice: PPAR alpha knockout mouse diaphragm and entropy production. Journal of Theoretical Biology, 2009, 250 (1), pp.92. 10.1016/j.jtbi.2007.09.022 . hal-00554496

\section{HAL Id: hal-00554496 https://hal.science/hal-00554496}

Submitted on 11 Jan 2011

HAL is a multi-disciplinary open access archive for the deposit and dissemination of scientific research documents, whether they are published or not. The documents may come from teaching and research institutions in France or abroad, or from public or private research centers.
L'archive ouverte pluridisciplinaire HAL, est destinée au dépôt et à la diffusion de documents scientifiques de niveau recherche, publiés ou non, émanant des établissements d'enseignement et de recherche français ou étrangers, des laboratoires publics ou privés. 


\section{Author's Accepted Manuscript}

Increased entropy production in diaphragm muscle of PPAR alpha knockout mice

Y. Lecarpentier, X. Krokidis, P. Martin, T. Pineau, J-L. Hébert, J. Quillard, M. Cortes-Morichetti, C. Coirault

PII: S0022-5193(07)00426-2

DOI: doi:10.1016/j.jtbi.2007.09.022

Reference: YJTBI 4846

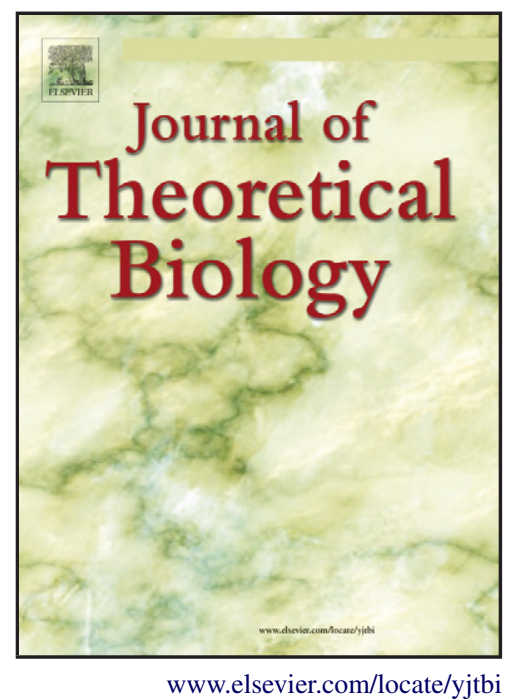

To appear in: $\quad$ Journal of Theoretical Biology

Received date: $\quad 11$ April 2007

Revised date: $\quad 13$ July 2007

Accepted date: $\quad 1$ September 2007

Cite this article as: Y. Lecarpentier, X. Krokidis, P. Martin, T. Pineau, J-L. Hébert, J. Quillard, M. Cortes-Morichetti and C. Coirault, Increased entropy production in diaphragm muscle of PPAR alpha knockout mice, Journal of Theoretical Biology (2007), doi:10.1016/j.jtbi.2007.09.022

This is a PDF file of an unedited manuscript that has been accepted for publication. As a service to our customers we are providing this early version of the manuscript. The manuscript will undergo copyediting, typesetting, and review of the resulting galley proof before it is published in its final citable form. Please note that during the production process errors may be discovered which could affect the content, and all legal disclaimers that apply to the journal pertain. 


\section{Increased entropy production in diaphragm muscle of}

\section{PPAR alpha knockout mice}

\section{Y. Lecarpentier ${ }^{\text {a, b }}$, X. Krokidis ${ }^{\text {a }}$, P. Martin ${ }^{\text {d, }}$ T. Pineau ${ }^{\text {, JJ-L. Hébert }}{ }^{\text {a }}$, J. Quillard ${ }^{\text {, }}$} M. Cortes-Morichetti ${ }^{\text {a }}$, C. Coirault ${ }^{\text {a, b }}$

${ }^{a}$ Service de Physiologie, Hôpital de Bicêtre, Assistance Publique-Hôpitaux de Paris, Université

Paris 11, Le Kremlin-Bicêtre, France.

${ }^{\boldsymbol{b}}$ Centre de Recherche Cardiovasculaire Inserm Lariboisière (CRCIL), U689, Hôpital

Lariboisière, Paris, France.

${ }^{c}$ Service d'Anatomo-Pathologie, Hôpital de Bicêtre, Assistance Publique-Hôpitaux de Paris,

Le Kremlin-Bicêtre, France.

${ }^{d}$ Inra, Chemin de Tournefeuille, Toulouse, France.

Running head: PPAR $\alpha$ knockout mouse diaphragm and entropy production

* Corresponding author: Y. LECARPENTIER MD, PhD, Service de Physiologie, Hôpital de Bicêtre, Assistance Publique-Hôpitaux de Paris, 94275, le Kremlin-Bicêtre, FRANCE.

TEL: (331) 45213662

FAX: (331) 45213778

E-mail: yves.lecarpentier@bct.ap-hp-paris.fr 


\begin{abstract}
Peroxisome proliferator activated receptor alpha (PPAR $\boldsymbol{x}$ ) regulates fatty acid $\beta$ oxidation and plays a central role in the metabolic and energetic homeostasis of striated muscles. The thermodynamic consequences of the absence of PPAR $\alpha$ were investigated in diaphragm muscle of PPAR $\alpha$ knockout mice (KO). Statistical mechanics provides a powerful tool for determining entropy production, which quantifies irreversible chemical processes generated by myosin molecular motors and which is the product of thermodynamic force A/T (chemical affinity A and temperature T) and thermodynamic flow (myosin crossbridge cycle velocity $\mathrm{u}$ ). The behavior of both wild type (WT) and KO diaphragm was shown to be nearequilibrium and in a stationary state, but $\mathrm{KO}$ was farther from equilibrium than WT. In KO diaphragm, a substantial decrease in contractile function was associated with an increase in both $\mathrm{A} / \mathrm{T}$ and $\mathrm{v}$ and with profound histological injuries such as contraction band necrosis. There were no changes in PPAR $\delta$ and $\gamma$ expression levels or myosin heavy chain patterns. In $\mathrm{KO}$ diaphragm, a marked increase in entropy production (A/T x $\mathrm{v})$ accounted for major thermodynamic dysfunction and a dramatic increase in irreversible chemical processes during the myosin crossbridge cycle.
\end{abstract}

Keywords: PPARa; Statistical mechanics; Entropy production; Diaphragm muscle; Thermoenergetics 


\section{Introduction}

Peroxisome proliferator activated receptors (PPARs) $\alpha, \beta / \delta$, and $\gamma$ belong to a family of nuclear receptors that regulate fatty acid metabolism via ligand-dependent transcriptional activation of target genes (Kliewer et al., 2001). PPAR $\alpha$ mediates lipid-induced activation of fatty acid $\beta$-oxidation (FAO) genes (Braissant et al., 1996). PPAR $\mathrm{R}$ is abundantly expressed in tissues characterized by high rates of FAO including liver and striated muscles such as diaphragm. A lack of PPAR $\alpha$ is expected to induce significant metabolic changes in cells in which it is highly expressed (Lefebvre et al., 2006). Thus, in PPAR $\alpha$ knockout (KO) mice, we hypothesized that diaphragm muscle (the most important inspiratory muscle) may present mechanical and thermodynamic abnormalities due to FAO dysfunction. We assessed the effects of PPAR $\alpha$ deficiency on myosin molecular motor mechanics and energetics in the diaphragm muscle of PPAR $\alpha$ knockout (KO) mice (Auwerx, 2006). We conducted an integrative study on the diaphragm muscle of KO and wild type (WT) mice focusing on myosin II crossbridge (CB) mechanics and biochemistry, cell histology and mRNA expression of the PPAR isotypes. Statistical mechanics were used to calculate entropy production and thereby quantify irreversible chemical processes in both WT and KO mouse diaphragm (Kondepudi and Prigogine, 1999).

Statistical mechanics have proved to be a powerful tool for establishing links between microscopic and macroscopic thermodynamic properties of physical systems (Atkins, 1990). Recently this formalism was used to show that the behavior of normal living skeletal muscles was near-equilibrium in a stationary state (Lecarpentier et al., 2005) (Demirel and Sandler, 2002; Dewey and Delle Donne, 1998; Kedem and Katchalsky, 1958; Kondepudi and Prigogine, 1999; Rigoulet et al., 1998; Stucki, 1980; Vidal et al., 1994). Such an approach stems from A.F. 
Huxley's phenomenological formalism of myosin II CB behavior in living muscles (Huxley, 1957) which makes it possible to determine the probabilities of several elementary steps of the actomyosin cycle (Lymn and Taylor, 1971). During this cycle, ATP is hydrolysed leading to a unidirectional movement of the myosin II molecular motor (Blomberg, 2006). In the present study, we showed that the behavior of KO mouse diaphragm was still near-equilibrium in a stationary state, but KO mouse diaphragm worked farther away from equilibrium than WT, as attested by a dramatic increase in entropy production generated by the contractile machinery. This coexisted with profound histological damage in the form of contraction band necrosis and waxy and granular degeneration of muscle cells. 


\section{Materials and Methods}

\section{1 Animals}

Protocols were approved by our institution, INSERM. Care of the animals conformed to the Helsinki declaration. Animals were 9-month-old male homozygous PPAR $\alpha$ knockout mice (KO) and were age-matched with wild type (WT) mice of the same genetic background (C57BL/6J from Charles River) (Lee et al., 1995). They were housed under controlled temperature $\left(20-22{ }^{\circ} \mathrm{C}\right)$ and lighting (12-h light-dark cycle) with free access to food and water.

\section{2 Muscle mechanics.}

Mechanical experiments were conducted on diaphragm muscle from $15 \mathrm{KO}$ and $14 \mathrm{WT}$ mice. Each diaphragm strip was rapidly mounted in a chamber containing a Krebs-Henseleit solution bubbled with $95 \% \mathrm{O}_{2}-5 \% \mathrm{CO}_{2}$ and maintained at $\mathrm{pH} 7.4$ and $26^{\circ} \mathrm{C}$. The strips were electrically stimulated by means of two platinum electrodes delivering tetanic stimulation (electrical stimulus: $1 \mathrm{~ms}$ duration; stimulation frequency: $50 \mathrm{~Hz}$; train duration: $250 \mathrm{~ms}$; train frequency: $0.17 \mathrm{~Hz}$ ). The electromagnetic lever system have been previously described (Lecarpentier et al., 1998). Muscle mechanical parameters and parameters determined from A.V Hill's equation have been described previously (Lecarpentier et al., 1998 ). The tensionvelocity $(\mathrm{P}-\mathrm{V})$ relationship was fitted according to $\mathrm{A}$. Hill's equation $(\mathrm{P}+\mathrm{a})(\mathrm{V}+\mathrm{b})=[\mathrm{Po}+\mathrm{a}] \mathrm{b}$ where $-\mathrm{a}$ and $-\mathrm{b}$ are the asymptotes of the hyperbola as determined by linear regression (Hill, 
1938). For each muscle strip, the P-V relationship was accurately fitted by a hyperbola (each $r$ $>0.98)$. The G curvature of A. Hill's equation is equal to Po / $\mathrm{a}=\mathrm{Vmax} / \mathrm{b}$, where Po is the peak isometric tension and Vmax is the maximum unloaded shortening velocity (Hill, 1938; Woledge et al., 1985). A.F. Huxley' s equations (Huxley, 1957) were used to calculate the maximum turnover rate of myosin ATPase under isometric conditions (kcat in s${ }^{-1}$ ), the elementary force per single $\mathrm{CB}(\pi 0$, in $\mathrm{pN})$ and the number of active $\mathrm{CBs}$ per cross-sectional area (N) (Coirault et al., 1997 ; Lecarpentier et al., 1998) (see the Appendix).

\subsection{Statistical mechanics.}

The physical formalism for statistical mechanics has been previously described (Lecarpentier et al., 2005). Briefly, the grand canonical ensemble is a general ensemble for applying statistical mechanics to complex open systems, such as living muscles, which exchange energy and matter with their surroundings. The muscle system $(\mathbf{S})$ was in a container $(\boldsymbol{C})$, both exchanging energy and matter. The system $\mathbf{S}$ was composed of all the cycling myosin heads that could individually be found in one of six distinct states (Fig.1). Among these different chemical conformations, CB myosin heads were either attached to or detached from actin, and they were bound or not to a nucleotide (ATP, ADP) or to Pi (Fig.1). The container $\boldsymbol{C}$ was composed of all the non-cycling myosin CBs, all the non-cycling actin molecules, and all the ATP and ADP and Pi which were not attached to the cycling CBs. Small soluble molecules (i.e., ATP, ADP and Pi) but also CBs and actin molecules can be exchanged between $\boldsymbol{S}$ and $\boldsymbol{C}$, 
so that the number of cycling CBs may slightly fluctuate with the number of non cycling CBs becoming cycling CBs and vice versa.

In the grand canonical ensemble, the average number of independent, noninteracting cycling CBs within the system was calculated from A.F. Huxley's equations (Huxley, 1957) and was equal to $N$. The grand canonical partition function $(\Xi)$ is linked to $E, S, N, T$ and $\mu$ according to the relations $\mathrm{E}-\mathrm{TS}-\sum \mu \mathrm{rdNr}=-\mathrm{kT} \ln \Xi$ (where $\mathrm{k}$ is the Boltzmann constant, $\mathrm{S}$ is the statistical entropy and $\mathrm{E}$ is the average internal energy of the system $\mathbf{S}$ and $\mu \mathrm{r}$ is the chemical potential of state r). Due to the highly organized lattice of striated muscles, CBs are independent and distinguishable molecules which can be named with a set of coordinates. The canonical partition function $\mathrm{Z}$ can be expressed as a function of the molecular partition function (z) as follows: $\mathrm{Z}=\mathrm{z}^{\mathrm{N}}$. E, $\mathrm{S}$ and $\mathrm{N}$ were determined in muscles isotonically contracting at constant shortening velocity under tetanic electrical stimulation. In the $\mathrm{CB}$ cycle, six different conformational states $r(r=0,1, \ldots, 5)$ at the energy level $\mathrm{E}_{\mathrm{r}}$ were individualized (Fig.1). Three states were detached states (D1, D2, and D3) ), i.e., CB was detached from actin and 3 states were attached states (A1, A2 and A3), i.e., CB was attached to actin.

$\mathrm{P}_{\mathrm{A} 1}, \mathrm{P}_{\mathrm{A} 2}$ and $\mathrm{P}_{\mathrm{A} 3}$ were the probabilities of states $\mathrm{A} 1, \mathrm{~A} 2$, and $\mathrm{A} 3$, respectively. $\mathrm{P}_{\mathrm{D} 1}, \mathrm{P}_{\mathrm{D} 2}$ and $\mathrm{P}_{\mathrm{D} 3}$ were the probabilities of states $\mathrm{D} 1, \mathrm{D} 2$, and $\mathrm{D} 3$, respectively. $\mathrm{P}_{\mathrm{A} 1}, \mathrm{P}_{\mathrm{A} 2}$, and $\mathrm{P}_{\mathrm{D} 1}$ were calculated from A.F. Huxley's equations (Lecarpentier et al., 2001). It has been previously reported that $\mathrm{P}_{\mathrm{D} 2}$ was equal to $10 \mathrm{P}_{\mathrm{D} 1}$ (Woledge et al., 1985). The method for determining $\mathrm{P}_{\mathrm{D} 3}$ and $\mathrm{P}_{\mathrm{A} 3}$ has been previously described (Lecarpentier et al., 2005). Briefly, the most probable state $r$ of the $\mathrm{CB}$ cycle was D3 and the least probable state $r$ of the CB cycle was A3 
(Lecarpentier et al., 2005). By convention, the energy of the lowest level, which coincided with the ground state, was equal to zero $\left(E_{D 1}=0\right)$ (Atkins, 1990). The highest state level (A3) was $\mathrm{E}_{\mathrm{A} 3}-\mathrm{E}_{\mathrm{D} 1}=\mathrm{E}_{\mathrm{A} 3}=5.1 \times 10^{-20} \mathrm{~J}$. The ratio of probabilities of the most probable state and the least probable state was given by the relation: $\mathrm{kT}\left(\ln \mathrm{P}_{\mathrm{D} 1} / \mathrm{P}_{\mathrm{A} 3}\right)=\mathrm{E}_{\mathrm{A} 3}$. Finally, $\mathrm{P}_{\mathrm{D} 3}=1-\left(\mathrm{P}_{\mathrm{Al}}+\mathrm{P}_{\mathrm{A} 2}+\right.$ $\mathrm{P}_{\mathrm{A} 3}+\mathrm{P}_{\mathrm{D} 1}+\mathrm{P}_{\mathrm{D} 2}$ ). Thus, the probability of each state $\mathrm{r}$ was determined. The statistical entropy $\mathrm{S}$ is given by the formula $S=-k N \sum_{r} P_{r} \ln P_{r}$. The Boltzmann distribution is given by the equation $P_{r}=e^{-\beta E_{r}} / \sum_{r} e^{-\beta E_{r}}$, where the molecular partition function is $z=\sum_{r} e^{-\beta E_{r}}=1$ / $P_{D 3} ;(\beta$ is equal to $1 / k T)$. The energy of each state $E_{r}$ was calculated from $e^{-\beta E_{r}}=z \times P_{r}$.

The fraction of CBs in the state $\mathrm{r}$ is given by $\mathrm{N}_{\mathrm{r}}=\mathrm{N} \times \mathrm{P}_{\mathrm{r}}$. The average number of cycling CBs (N) in the grand canonical ensemble is equal to $\sum_{\mathrm{r}} \mathrm{N}_{\mathrm{r}}$. The average internal energy of the system $\mathrm{S}$ is $\mathrm{E}=\sum_{\mathrm{r}} \mathrm{N}_{\mathrm{r}} \mathrm{E}_{\mathrm{r}}$. According to the relation Emol $-\mathrm{TSmol}-\sum \mu \mathrm{rdNrmol}=-\mathrm{RT} \ln$ $\Xi$, the CB cycle stopped when the velocity of the system $v$ tended towards zero; (Nrmol: mole number in state r). Affinity per mole (A) of the CB cycle is the sum of affinity of the constituent chemical reactions over the $\mathrm{CB}$ cycle. Affinity is equal to $\mathrm{A}=-\sum \mu \mathrm{rdNr}$ mol $=\sum_{\mathrm{r}} \mathrm{A}_{\mathrm{r}}$ (Kondepudi and Prigogine, 1999). A tended towards zero when $v$ tended towards zero. Then, Emol - TSmol tended towards - RT $\ln \Xi$, (where Emol is the molar internal energy and Smol is the molar entropy). 


\section{4. Entropy production due to chemical reactions.}

The formalism for expressing entropy change $d S$ as a sum of two parts is $d S=d_{e} S+$ $d_{i} S$, where $d_{e} S$ is the entropy change due to exchange of matter and energy with the exterior and $\mathrm{d}_{\mathrm{i}} \mathrm{S}$ is the entropy change due to the irreversible chemical processes within the system (diS is always negative) (Prigogine, 1967). In a stationary state, the total entropy of the system remains constant, i.e., $\mathrm{dS} / \mathrm{dt}=\mathrm{deS} / \mathrm{dt}+\mathrm{diS} / \mathrm{dt}=0$, which means the entropy exchange with the exterior must be negative: $\mathrm{deS} / \mathrm{dt}=-\mathrm{diS} / \mathrm{dt}<0$. De Donder (De Donder, 1927) established a clear connection between entropy production and irreversible chemical reactions. In open systems in the linear regime, entropy production due to a chemical reaction is $\mathrm{d}_{\mathrm{i}} \mathrm{S} / \mathrm{dt}=(\mathrm{A} / \mathrm{T}) \mathrm{x}$ $v>0$. Entropy production $d_{i} S / d t$ is the product of thermodynamic force $(A / T)$ and thermodynamic flow $(v=$ kcat $x$ mole number per liter $)$. When affinity $A$ is $<<2500 \mathrm{~J} / \mathrm{mol}$, a chemical system is near equilibrium. Moreover, a near-equilibrium chemical system is in a stationary state if thermodynamic force varies linearly with thermodynamic flow. In stationary states, Prigogine's theorem can be applied (Prigogine, 1967): in a linear regime, total entropy production in a system subject to flow of energy and matter reaches a minimum value at the non equilibrium stationary state. 


\section{5. Histology.}

Histology was performed on 10\%-formalin-treated diaphragm tissue. Paraffinembedded sections were stained with hematoxylin-eosin-saffron (HES stain), Masson trichrome (MT stain), or periodic acid-Schiff stain (PAS stain).

\subsection{Myosin heavy chain (MHC) electrophoresis.}

Preparations of crude myosin were obtained from the ventral part of the costal diaphragm, as previously described (Coirault et al., 2003). MHC were separated in sodium dodecyl sulfate-polyacrylamide (SDS-PAGE) minigel electrophoresis (Agbulut et al., 1996). The amount of each isoform was determined by the area of each peak. Long-duration electrophoresis was performed in a BioRad Mini-Protean II Dual Slab Cell electrophoresis system for $32 \mathrm{~h}$ at $4^{\circ} \mathrm{C}$ and $70 \mathrm{~V}$. MHC were separated in dissociating conditions with 0.75 mM sodium dodecyl sulfate-polyacrylamide (SDS-PAGE) minigel electrophoresis. Stacking gel was composed of $4 \%$ acrylamide (2.67\% bis-acrylamide), $70 \mathrm{mM}$ Tris (pH 6.8), 30\% glycerol, 4 mM EDTA and 0.1\% SDS. The composition of the separating gel was $8 \%$ acrylamide (1\% bis-acrylamide), 0.2 M Tris $\mathrm{pH} 8.8,0.1 \mathrm{M}$ glycine and $0.4 \%$ SDS. Separate upper and lower running buffers were used. The upper running buffer consisted of $0.1 \mathrm{M}$ Tris, $150 \mathrm{mM}$ glycine, $11.5 \mathrm{mM}$ 2-mercaptoethanol and 0.1\% SDS. The lower running buffer consisted of $50 \mathrm{mM}$ Tris, $75 \mathrm{mM}$ glycine and $0.05 \%$ SDS. Both buffers were prepared shortly before use and cooled at $4{ }^{\circ} \mathrm{C}$. Gels were stained with $0.2 \%$ Coomassie blue, $50 \%$ ethanol and $10 \%$ acetic acid. They were destained with $5 \%$ ethanol and 5\% acetic acid. 
2.7. RT- PCR.

Real-time PCR experiments were performed using TaqMan Gene Expression Assays from Applied Biosystems (Mm00803184 m1 for PPAR $\delta$, Mm00440945 m1 for PPAR $\gamma$ and Mm00446973_m1 for TBP [TATAbox-Binding Protein]) on an ABI-Prism 7000 system (Martin et al., 2005). Quantification was performed using standard curves obtained from pools of liver (for PPAR $\delta$ and TBP) or from white adipose tissue cDNA (for PPAR $\gamma$ ). Data for both PPARs are normalized by the corresponding values for TBP. Normalized data are presented as mean \pm standard deviation ( $\mathrm{n}=4$ and 5 for $\mathrm{WT}$ and $\mathrm{KO}$ mice respectively). Total RNAs were extracted from liquid nitrogen-frozen diaphragm samples using TRIzol solution (Invitrogen, Cergy-Pontoise, France). Reverse transcription was carried out using Superscript II reverse transcriptase (Invitrogen, Cergy-Pontoise, France).

\section{7 Statistical analysis.}

Data are expressed as means \pm standard error of the mean (SEM), except for RT-PCR data which are presented as mean \pm standard deviation. Parameters of WT and KO mouse groups were compared using Student ' s unpaired t-test. A p value $<0.05$ was considered statistically significant. Linear regressions were based on the least squares method.

\section{Results}

3. 1.Animals and diaphragm muscle characteristics. 
Body weight was heavier in KO than in WT $(41.0 \pm 1.5$ versus $34.5 \pm 2.5 \mathrm{~g} ; \mathrm{p}<0.05)$. There were no significant differences between the KO and WT groups in muscle length $(8.8 \pm 0.5$ and $8.5 \pm 0.4 \mathrm{~mm}$, respectively) and muscle cross-sectional area $(0.51 \pm 0.04$ and $0.48 \pm$ $0.04 \mathrm{~mm}^{2}$, respectively) of the diaphragm samples.

\section{2. Diaphragm muscle and CB mechanics.}

The muscle mechanical parameters, molecular CB characteristics and statistical mechanics of WT and KO are presented in Table1. Maximum unloaded shortening velocity $\left(\mathrm{V}_{\max }\right)$, total isometric tension $(\mathrm{Po}), \mathrm{CB}$ number $/ \mathrm{mm}^{2}(\mathrm{~N})$, unitary $\mathrm{CB}$ force $\left(\pi_{0}\right)$ and muscle peak efficiency (Effmax) were markedly decreased in KO as compared to WT. Moreover, CB kinetics were considerably changed, as attested by changes in the CB detachment constants ( $\mathrm{g}_{1}$ and $\left.g_{2}\right)$.

\section{3. Thermodynamics.}

- Statistical mechanics are shown in Table 2 and Figs.2 and 3. The microcanonical partition function $(\mathrm{z})$, the logarithm of canonical partition function $(\ln \mathrm{Z})$ and the logarithm of grand canonical partition function (ln $\Xi$ ) were significantly higher in KO than in WT. Molar statistical entropy (S) and molar internal energy (E) were also significantly higher in $\mathrm{KO}$ than in WT (Table 2). Grand potential per mole was $-130{\mathrm{~J} . \mathrm{mol}^{-1}}^{-1} \mathrm{WT}$ and $-175 \mathrm{~J}_{\mathrm{mol}} \mathrm{m}^{-1}$ in KO. Moreover, CB cycle velocity (u), i.e., thermodynamic flow, and affinity / T (A/T), i.e., 
thermodynamic force, were higher in KO than in WT (Fig.2). Consequently, entropy production, which is the product of $v$ and $\mathrm{A} / \mathrm{T}$, was markedly higher in $\mathrm{KO}$ than in WT. Importantly, in both WT and KO, affinity (A) was $<<2500 \mathrm{~J} / \mathrm{mol}$ (Fig.2), indicating that WT and KO diaphragm muscles were near-equilibrium (Kondepudi and Prigogine, 1999). Moreover, thermodynamic force (A/T) and thermodynamic flow (v) varied linearly (Fig.3), indicating that WT and KO mouse diaphragms were stationary systems. Entropy production was linearly and positively related to microcanonical partition function (z) (Fig.3). Conversely, entropy production was linearly and negatively related to unitary CB force and peak muscle efficiency (Fig.3). The absolute values of the slope of these negative linear relationships (Fig.3) were greater in $\mathrm{KO}$ than in WT mouse diaphragm $(\mathrm{p}<0.05)$. There were no relationships between entropy production and macroscopic mechanical parameters such as Vmax and total tension.

\section{4. Histological diaphragm analysis.}

Diaphragm muscle from WT mice did not show any histological abnormalities (Fig.4). Diaphragm from the KO mice showed muscle myofibrillar degeneration leading to sarcomere disorganization and the focal disappearance of striation (Fig.4). Two stages of muscle degeneration were observed in KO diaphragm (Adams et al., 1954): waxy degeneration (Fig.4), which is a coagulation necrosis, and granular degeneration (Fig.4), which is liquefaction necrosis. Waxy degeneration appeared as an accumulation of clear watery vacuoles of varying size in the muscle sarcoplasm and represented a vacuolar degeneration swelling of part of the muscle fiber, which is a less advanced stage than granular degeneration. Granular degeneration is considered a more severe and irreversible form of waxy degeneration. The granules were 
scattered irregularly throughout the fiber. In KO mouse diaphragm, there were no PAS-positive vacuoles nor any evidence of increased fibrosis in KO Masson-trichrome sections as compared to WT (Fig.4).

\section{5. Myosin heavy chain composition.}

Mouse diaphragm was composed of 4 myosin heavy chain (MHC) isoforms (Fig.5). In WT, fast fiber type $2 \mathrm{X}$ predominated and represented about $60 \%$ of total MHC, whereas slow fiber type I represented only about $10 \%$. No differences in MHC isoform pattern were observed between WT and KO (Fig.5).

3. 6. $m R N A$ expression of PPAR isotypes.

Given that PPAR $\delta$ might compensate for PPAR $\alpha$ deficiency, mRNA expression of PPAR $\delta$ and $\gamma$ subtypes were also investigated using quantitative RT-PCR. No significant differences in PPAR $\delta$ or PPAR $\gamma$ transcript expression were observed in WT and KO mouse diaphragm (Fig.5). 


\section{Discussion}

\section{1. Mechanical, biochemical and histological changes in PPAR knockout mouse diaphragm} muscle.

This study showed that lack of PPAR $\alpha$ considerably modified the mechanics and energetics of PPAR k knockout mouse diaphragm muscle. Muscle mechanics were impaired, as attested by a decrease in both total tension and unloaded muscle shortening velocity (Table1). These results were supported by the presence of histological injuries in KO (Fig.4). The mechanical abnormalities occurred despite the fact that there were no differences in myosin heavy chain composition or mRNA expression levels of PPAR $\delta$ and $\gamma$ between KO and WT (Fig. 5). Importantly, at the molecular level, CB properties of KO diaphragm were impaired, as shown by the decrease in the number of active CBs and unitary CB force and by alterations in CB kinetics (Table1). Changes in CB mechanical properties and in statistical mechanics observed in $\mathrm{KO}$ animals cannot be explained by differences in myosin heavy chain composition or mRNA expression levels of PPAR $\delta$ and $\gamma$ between KO and WT (Fig. 5).

\subsection{A.F. Huxley's formalism and statistical mechanics.}

Thermodynamic informations provided by Huxley's equations are major per se. However, these equations described the kinetics of only three steps of the crossbridge cycle: the 
attachment step (A1), the stroke step (A2) and the detachment step (D1) (Fig.1). The three others were determined through the use of statistical mechanics. Importantly, the detached step (D3) (which is the most probable step) was not derived from Huxley's formalism and played a central role in statistical mechanics due to the fact that its probability (PD3) is simply linked to the microcanonical partition function $(\mathrm{z}=1$ / Prob D3). Calculation of the entropy production required both Huxley's equations and statistical mechanics and could not be calculated solely with Huxley's formalism. Huxley's equations allowed to calculate the reaction velocity (i.e. the thermodynamic flow). Statistical mechanics allowed to calculate the affinity A and consequently the thermodynamic force (A/T). Although Huxley's equations represent a powerful tool, the introduction of statistical mechanics made it possible to go further in our thermodynamic analysis. Introduction of statistical mechanics offered the major advantage of enabling the calculation of the main thermodynamic functions and the determination of the distance from equilibrium.

\section{3 Near-equilibrium thermodynamics and linear regime.}

In both WT and KO mouse diaphragms, the approach of near-equilibrium thermodynamics was valid because affinity was $<<2500 \mathrm{~J} . m o l^{-1}$ (Fig.1) (Kondepudi and Prigogine, 1999; Prigogine, 1967; Vidal et al., 1994) (Fig.1). In living cells, numerous enzymatic systems which regulate metabolism have been shown to be in near-equilibrium. Some of them involving ATP, such as the glyceraldehyde-3-phosphate deshydrogenase-3phosphoglycerate kinase enzymatic complex, creatine kinase and myokinase which play a key role in muscle function, have been shown to be in near-equilibrium in various cells (Marshall 
and Omachi, 1974; Veech et al., 1979). Interestingly, the Gibbs-Donnan system in heart muscle (Masuda et al., 1990) and the $\mathrm{Na}^{+}-\mathrm{K}^{+}$ATPase in all tissues (Veech et al., 2002) are in nearequilibrium.

Because of the linearity between thermodynamic force (A/T) and thermodynamic flow (v), the approach of linear near-equilibrium thermodynamics could be applied in our study (Fig.3). In living cells, linear near-equilibrium thermodynamics (Demirel and Sandler, 2002) have been applied to various fields including oxidative phosphorylation and mitochondria (Rigoulet et al., 1998; Stucki, 1980), facilitated and active transport (Kedem and Katchalsky, 1958; Stucki, 1980), and time evolution of proteins (Dewey and Delle Donne, 1998). In our study, the linearity between affinity $(\mathrm{A} / \mathrm{T})$ and $\mathrm{CB}$ cycle velocity $(\mathrm{U})$ provided evidence that mouse diaphragms were in stationary states, but with large differences in entropy production. In stationary states, it has been shown that total entropy production reaches a minimum, which is the stability criterion (Kondepudi and Prigogine, 1999; Prigogine, 1967).

\section{43 Statistical entropy}

Due to the huge number of $\mathrm{CBs}$ involved in contractile processes, muscle tissue presents the necessary ground for applying statistical mechanics. Therefore, a combination of statistical mechanics (Levine, 2003) and A.F. Huxley’s formalism (Huxley, 1957) can be used to determine macroscopic thermodynamic properties of living muscles, particularly statistical entropy (Atkins, 1990 ; Backx, 1993). The grand canonical ensemble provides a general method for applying statistical mechanics to complex open systems such as living muscles (Lecarpentier et al., 2005). Statistical entropy is related to the dispersal of energy and is a measure of the degree of disorder in a given system. Statistical molar entropy was markedly 
higher in KO than in WT diaphragm muscles (Table 2). Thus, the organizational level of myosin II molecular motors can be considered to be lower in KO than in WT. The higher statistical entropy observed in KO compared with WT coincided with lower unitary CB force (Tables 1 and 2). As previously described in rat skeletal muscle, statistical entropy has been shown to be lower in slow muscle than in fast muscle, and correlatively unitary CB force is higher in slow than in fast skeletal muscle (Lecarpentier et al., 2005). Moreover, a decrease in $\mathrm{CB}$ force has been previously reported in pathophysiological states such as heart failure (Lecarpentier et al., 1998), chronic growth hormone hypersecretion (Lecarpentier et al., 1999) and muscular dystrophy (Coirault et al., 1999). The uncertainty concerning the experimental values of distance between two actin sites (1) and the myosin step size (h) makes it difficult to determine the CB single force through Huxley's equations and thus represents a limitation.

The molecular partition function (z) was higher in KO than in WT (Table 2). This function contains all the thermodynamic information about a given system and reflects how the total number of molecular motors is distributed - partitioned - over the available states. The numerical value of $\mathrm{z}$ gives a very rough estimate of the number of molecular states that are significantly populated at $\mathrm{T}\left({ }^{\circ} \mathrm{K}\right)$.

\section{5 Entropy production}

Statistical entropy measures the organizational status of a system and depicts the evolution of this system at a given time. However entropy does not drive, cause or affect the evolution of the system, which is assigned to entropy production. Entropy production quantifies irreversibility. The absence of PPAR $\alpha$ in KO diaphragm led to an increase in entropy production, i.e., in irreversible chemical processes in CB molecular motors, and increased the 
distance from equilibrium as compared to WT. An increase in both thermodynamic flow (CB cycle velocity $\mathrm{U})$ and thermodynamic force $(\mathrm{A} / \mathrm{T})$ contributed to increased entropy production (Fig.2). Although KO mouse diaphragm behavior was still near equilibrium and in stationary state, $\mathrm{KO}$ near-equilibrium status differed from that of WT and the distance from equilibrium was greater in KO than in WT (Fig.2) (De Donder, 1927; Prigogine, 1967; Prigogine, 1986).The higher the rate of entropy production, the further the system moves away from equilibrium.

The way in which the thermodynamic shift between WT and KO occurred remains to be determined. A possibility might be a progressive shift from a near equilibrium position towards a new one. However, it has been shown that certain biological systems can be driven discontinuously to new types of regimes corresponding to different stationary or steady states (Babloyantz and Nicolis, 1972). Chemical instabilities and multiple steady state transitions have been demonstrated (Monod and Jacob, 1961). Thus, in certain types of non-linear systems, the stability of steady states is not guaranteed once they are maintained sufficiently far from equilibrium (Glansdorff and Prigogine, 1971). Biological systems undergo unstable transitions and then evolve to new types of cellular organization (Blumenthal et al., 1970). These transition phenomena between different pathways have been shown to be related to system asymmetry resulting from non-equilibrium coupling to the environment, and are similar to the transitions leading to dissipative structures (Glansdorff and Prigogine, 1971). Such chemical instabilities and bifurcations that occur far from equilibrium might account for transitions to new steady (or stationary) states (Blumenthal et al., 1970; Lefever and Horsthemke, 1979; Lefever and Nicolis, 1971; Nicolis, 1977). 


\section{6. Thermodynamics, metabolism and PPAR}

The profound thermodynamic changes observed in $\mathrm{KO}$ mouse diaphragm were probably due in part to the absence of PPAR $\alpha$. This was reinforced by the fact that there were no differences in expression levels of PPAR $\delta$ and $\gamma$ between KO• and WT (Fig.5). By mediating lipid-induced activation of FAO genes (Braissant et al., 1996), PPARe plays a crucial role in promoting $\beta$-oxidative pathway. Thus, PPAR $\alpha$ deficiency may alter muscle gene regulation and skeletal muscle fuel metabolism. In vivo administration of PPARe-selective agonists activates muscle genes promoting selective utilization of lipid substrates (Kelly et al., 1998; Wu et al., 1999). PPAR $\alpha$ regulates fatty acid utilization and mRNA expression of several FAO genes in human skeletal muscle (Muoio et al., 2002). Since ATP availability and contractile function are closely linked, it is reasonable to assume that absence of PPAR $\alpha$ leading to diminished fatty acid oxidation and reduced production of ATP might be involved in the compromise of diaphragm function in PPAR $\alpha-/-$ mice.

It has been shown that, except when animals were starved, skeletal muscles from PPAR

$\alpha^{-/-}$mice exhibit minor changes in fatty acid homeostasis (Muoio et al., 2002). Moreover, PPARs induces multiple pathways that cooperatively promote FAO, a function that is generally assigned to PPARx. In both human and rodent skeletal muscles, activation of PPARsincreases the FAO and mRNA levels of several PPAR $\alpha$ target genes. Redundancy in the role of PPAR $\alpha$ and $\delta$ as transcriptional regulators of fatty acid homeostasis has been demonstrated, suggesting that high levels of PPAR $\delta$ can compensate for PPAR $\alpha$ deficiency in skeletal muscle (Muoio et al., 2002). 
In terms of PPAR expression levels, PPAR $\delta$ predominates in heart and skeletal muscles (Luquet et al., 2003 ; Muoio et al., 2002 ; Wang et al., 2004). However, diaphragm muscle differs from other skeletal muscles and seems to be similar to heart muscle, at least in rat and as far as the PPAR system is concerned (Escher et al., 2001). Both PPAR $\alpha$ and $\delta$ expression is much higher in heart and diaphragm muscles than in skeletal muscles. Moreover, PPAR $\delta$ has been shown to drive the synthesis of type I muscle fibers (Wang et al., 2004). Endurance training enhances muscle metabolic performance and PPAR $\delta$ is responsible for engineering the oxidative fiber shift. Several arguments suggest that in KO mouse diaphragm PPAR $\delta$ did not compensate for PPAR $\alpha$ deficiency. The MHC isoform pattern was similar in WT and KO (Fig.4). In both WT and KO, the percentage of slow fatigue-resistant type1 fibers was similar and type $2 \mathrm{X}$ fibers, which are susceptible to fatigue, dominated. Moreover, mRNA expression levels of PPAR $\delta$ and $\gamma$ were similar in WT and KO (Fig.5). Peak efficiency of mouse diaphragm was lower in KO than in WT (Table 1; Fig.3). Histological abnormalities described in diaphragm muscle of $\mathrm{KO}$ mice helped to explain the seriousness of the mechanical and energetic alterations (Fig.4).

In summary, lack of PPAR $\alpha$ considerably impaired the mechanics and energetics of PPARa knockout mouse diaphragm muscle and led to histological injuries. KO diaphragm was shown to be near-equilibrium and in a stationary state, but was farther from equilibrium than that of WT. At the molecular level, CB properties of KO diaphragm were impaired, as attested by the decrease in the number of active $\mathrm{CBs}$ and unitary $\mathrm{CB}$ force and by alterations in $\mathrm{CB}$ kinetics. These abnormalities occurred although there were no differences in myosin heavy 
chain composition or mRNA expression levels of PPAR $\delta$ and $\gamma$ between KO and WT. In KO diaphragm, a marked increase in entropy production accounted for major thermodynamic dysfunction and a dramatic increase in irreversible chemical processes during the myosin crossbridge cycle. 


\section{Appendix}

\section{CB characteristics}

The rate of total energy release $\left(\mathrm{E}_{\mathrm{Hux}}\right)$ and the isotonic tension $\left(\mathrm{P}_{\mathrm{Hux}}\right)$ as a function of muscle velocity (V) are given by A. F. Huxley’s equations (Huxley, 1957):

$$
\begin{aligned}
& E_{\text {Hux }}=\mathrm{Ne} \frac{\mathrm{h}}{2 l} \frac{\mathrm{f}_{1}}{\mathrm{f}_{1}+\mathrm{g}_{1}}\left\{\mathrm{~g}_{1}+\mathrm{f}_{1} \frac{\mathrm{V}}{\phi}\left(1-\mathrm{e}^{-\frac{\phi}{\mathrm{V}}}\right)\right\} \\
& \mathrm{P}_{\text {Hux }}=\mathrm{N} \frac{\mathrm{sw}}{2 \mathrm{l}} \cdot \frac{\mathrm{f}_{1}}{\mathrm{f}_{1}+\mathrm{g}_{1}}\left\lfloor 1-\frac{\mathrm{V}}{\phi}\left(1-\mathrm{e}^{\frac{\phi}{\mathrm{V}}}\right)\left(1+\frac{1}{2}\left(\frac{\mathrm{f}_{1+\mathrm{g}_{1}}}{\mathrm{~g}_{2}}\right)^{2} \frac{\mathrm{V}}{\phi}\right)\right\rfloor
\end{aligned}
$$

where $\mathrm{N}$ is the cycling $\mathrm{CB}$ number per $\mathrm{mm}^{2}$ at peak isometric tension; $\mathrm{s}$ is the resting optimal sarcomere length $(\mathrm{s}=2.2 \mu \mathrm{m}) ; \mathrm{f}_{1}$ is the peak value of the rate constant for $\mathrm{CB}$ attachment; and $\mathrm{g}_{1}$ and $\mathrm{g}_{2}$ are the peak values of the rate constants for CB detachment. The tilt of the myosin head relative to actin varies from 0 to $h ; f_{1}$ and $g_{1}$ correspond to a tilt $=0$, and $\mathrm{g}_{2}$ corresponds to a tilt $>\mathrm{h} ; \phi=\left(\mathrm{f}_{1}+\mathrm{g}_{1}\right) \mathrm{h} / \mathrm{s}=\mathrm{b}$.

w i s the maximum mechanical work of a single CB (w / e = 0.75) (Huxley, 1957). According to A.F. Huxley's theory (Huxley, 1957) one ATP molecule is split per CB cycle. The standart free energy $\Delta \mathrm{G}^{\circ}{ }_{\text {ATP }}$, e is equal to $5.1 \times 10^{-20} \mathrm{~J}$ (Woledge et al., 1985); $\Delta \mathrm{G}^{\circ}{ }_{\text {ATP }}$ has been found to be $-32 \mathrm{~kJ} / \mathrm{mol}$ at $\mathrm{pH} 7.0$ and $37^{\circ} \mathrm{C}$ (Veech et al., 1979).

The parameter 1 is the distance between successive actin sites with which any one myosin site can combine. In Huxley's work (Huxley, 1957), the calculated estimate of 1 has been found to 
be $15.3 \mathrm{~nm}$. This value approximately corresponds to the meridional spot at $14.3 \mathrm{~nm}$ determined by means of X-ray diffraction and arising from the helical arrangement of crossbridges on the thick filament (Squire, 1981). This is of same order of magnitude than the distance corresponding to three successive G-actin monomers. Considering a given actin filament, the distance 1 between two actin sites with which a myosin site can attach was chosen to be equal to $14.3 \mathrm{~nm}$. The molecular step size $\mathrm{h}$ is defined by the translocation distance of the actin filament per ATP hydrolysis, produced by the swing of the myosin head (Huxley, 1969). A.F. Huxley's equations assume that 1 is much greater than $h$. The value of $h$ was chosen to be equal equal to $5 \mathrm{~nm}$, a value supported by optical tweezers experiments on muscle myosin II (Molloy et al., 1995).

Calculations of $\mathrm{f}_{1}, \mathrm{~g}_{1}$, and $\mathrm{g}_{2}$ are given by the following equations (Lecarpentier et al., 1998):

$$
\begin{aligned}
& \mathrm{G}=\mathrm{f}_{1} / \mathrm{g}_{1} ; \quad \mathrm{g}_{1}=\frac{\mathrm{swb}}{\mathrm{ehG}} ; \quad \mathrm{g}_{2}=\frac{\mathrm{sV_{ \operatorname {max } }}}{\mathrm{h}} \\
& \mathrm{k}_{\text {cat }}=(\mathrm{h} / 2 \mathrm{l}) \times\left[\left(\mathrm{f}_{1} \mathrm{~g}_{1}\right) /\left(\mathrm{f}_{1}+\mathrm{g}_{1}\right)\right] \text { and } \pi 0=(\mathrm{w} / \mathrm{l}) \times\left[\left(\mathrm{f}_{1}\right) /\left(\mathrm{f}_{1}+\mathrm{g}_{1}\right)\right]
\end{aligned}
$$

The number of active CBs $(\mathrm{N})$ is equal to the ratio of the peak isometric tension and the elementary CB force $(\pi 0)$.

The rate of mechanical work $\left(\mathrm{W}_{\mathrm{M}}\right)$ is given by the equation : $\mathrm{W}_{\mathrm{M}}=\mathrm{P}_{\text {Hux }} \cdot \mathrm{V}$

At any given load level, the mechanical efficiency (Eff) of the muscle is defined as the ratio of $\mathrm{W}_{\mathrm{M}}$ to $\mathrm{E}_{\mathrm{Hux}}$ i.e., $\mathrm{Eff}=\mathrm{W}_{\mathrm{M}} / \mathrm{E}_{\mathrm{Hux}}$ and $\mathrm{Eff}_{\max }$ is the peak value of Eff. 


\section{References}

Adams, R. D., Denny-Brown, D., and Pearson, C. M. 1954. Diseases of muscle (New York, Paul B. Hoeber, INC).

Agbulut, O., Li, Z., Mouly, V., and Butler-Browne, G. S. 1996. Analysis of skeletal and cardiac muscle from desmin knock-out and normal mice by high resolution separation of myosin heavy-chain isoforms. Biol Cell 88, 131-135.

Atkins, P. W. 1990. Physical Chemistry, fifth edition edn ( Oxford Melbourne Tokio, Oxford University Press).

Auwerx, J. 2006. Improving metabolism by increasing energy expenditure. Nat Med 12, 44-45. Babloyantz, A., and Nicolis, G. 1972. Chemical instabilities and multiple steady state transitions in Monod-Jacob type models. J Theor Biol 34, 185-192.

Backx, P. 1993. Efficiency of cardiac muscle: thermodynamic and statistical mechanical considerations. basic Res Cardiol 88 Suppl 2, 21-28.

Blomberg, C. 2006. Fluctuations for good and bad: The role of noise in living systems. Physics of Life Reviews 3, 133-161.

Blumenthal, R., Changeux, J.P., and Lefever, R. 1970. [A theory of electric excitation of biological membranes]. C R Acad Sci Hebd Seances Acad Sci D 270, 389-392.

Braissant, O., Foufelle, F., Scotto, C., Dauca, M., and Wahli, W. 1996. Differential expression of peroxisome proliferator-activated receptors (PPARs): tissue distribution of PPAR-alpha, beta, and -gamma in the adult rat. Endocrinology 137, 354-366.

Coirault, C., Lambert, F., Joseph, T., Blanc, F. X., Chemla, D., and Lecarpentier, Y. 1997. Developmental changes in crossbridge properties and myosin isoforms in hamster diaphragm. Am J Respir Crit Care Med 156, 959-967. 
Coirault, C., Lambert, F., Marchand-Adam, S., Attal, P., Chemla, D., and Lecarpentier, Y.1999. Myosin molecular motor dysfunction in dystrophic mouse diaphragm. Am J Physiol 277, C1170-1176.

Coirault, C., Pignol, B., Cooper, R. N., Butler-Browne, G., Chabrier, P. E., and Lecarpentier, Y. 2003. Severe muscle dysfunction precedes collagen tissue proliferation in mdx mouse diaphragm. J Appl Physiol 94, 1744-1750.

De Donder, T. (1927). L' affinité, Gauthiers-Villars. edn (Paris).

Demirel, Y., and Sandler, S. I. 2002. Thermodynamics and bioenergetics. Biophys Chem 97, 87-111.

Dewey, T. G., and Delle Donne, M. 1998. Non-equilibrium thermodynamics of molecular evolution. J Theor Biol 193, 593-599.

Escher, P., Braissant, O., Basu-Modak, S., Michalik, L., Wahli, W., and Desvergne, B. 2001. Rat PPARs: quantitative analysis in adult rat tissues and regulation in fasting and refeeding. Endocrinology 142, 4195-4202.

Glansdorff, P., and Prigogine, I. 1971. Thermodynamics of structure stability and fluctuations, Wiley, J. edn (New York).

Hill, A. V. 1938. The heat of shortening and the dynamic constants of muscle. Proc R Soc Lond Biol Sci 126, 136-195.

Huxley, A. F. 1957. Muscle structure and theories of contraction. Prog Biophys Biophys Chem 7, 255-318.

Huxley, H. E. 1969. The mechanism of muscular contraction. Science 164, 1356-1365. Kedem, O., and Katchalsky, A. 1958. Thermodynamic analysis of the permeability of biological membranes to non-electrolytes. Biochim Biophys Acta 27, 229-246. 
Kelly, L. J., Vicario, P. P., Thompson, G. M., Candelore, M. R., Doebber, T. W., Ventre, J., Wu, M. S., Meurer, R., Forrest, M. J., Conner, M. W., et al. 1998. Peroxisome proliferatoractivated receptors gamma and alpha mediate in vivo regulation of uncoupling protein (UCP-1, UCP-2, UCP-3) gene expression. Endocrinology 139, 4920-4927.

Kliewer, S. A., Xu, H. E., Lambert, M. H., and Willson, T. M. 2001. Peroxisome proliferatoractivated receptors: from genes to physiology. Recent Prog Horm Res 56, 239-263.

Kondepudi, D., and Prigogine, I. 1999. Modern thermodynamics from heat engines to dissipative structures (New York, Wiley \& Sons).

Lecarpentier, Y., Blanc, F. X., Quillard, J., Hebert, J. L., Krokidis, X., and Coirault, C. 2005. Statistical mechanics of myosin molecular motors in skeletal muscles. J Theor Biol 235, 381392.

Lecarpentier, Y., Chemla, D., Blanc, F. X., Pourny, J. C., Joseph, T., Riou, B., and Coirault, C. 1998. Mechanics, energetics, and crossbridge kinetics of rabbit diaphragm during congestive heart failure. Faseb J 12, 981-989.

Lecarpentier, Y., Chemla, D., Pourny, J. C., Blanc, F. X., and Coirault, C. 2001. Myosin cross bridges in skeletal muscles: "rower" molecular motors. J Appl Physiol 91, 2479-2486.

Lecarpentier, Y., Coirault, C., Riou, B., Chemla, D., and Mercadier, J. J. 1999. Diaphragm strength and cross-bridge properties during chronic growth hormone hypersecretion. Eur Respir J 13, 1070-1077.

Lee, S. S., Pineau, T., Drago, J., Lee, E. J., Owens, J. W., Kroetz, D. L., Fernandez-Salguero, P. M., Westphal, H., and Gonzalez, F. J. 1995. Targeted disruption of the alpha isoform of the peroxisome proliferator-activated receptor gene in mice results in abolishment of the pleiotropic effects of peroxisome proliferators. Mol Cell Biol 15, 3012-3022. 
Lefebvre, P., Chinetti, G., Fruchart, J. C., and Staels, B. 2006. Sorting out the roles of PPARalpha in energy metabolism and vascular homeostasis. J Clin Invest 116, 571-580.

Lefever, R., and Horsthemke, W. 1979. Bistability in fluctuating environments. Implications in tumor immunology. Bull Math Biol 41, 469-490.

Lefever, R., and Nicolis, G. 1971. Chemical instabilities and sustained oscillations. J Theor Biol 30, 267-284.

Levine, I. N. 2003. Physical chemistry, Fith edition, McGraw-Hill International Edition edn (New York).

Luquet, S., Lopez-Soriano, J., Holst, D., Fredenrich, A., Melki, J., Rassoulzadegan, M., and Grimaldi, P. A. 2003. Peroxisome proliferator-activated receptor delta controls muscle development and oxidative capability. Faseb J 17, 2299-2301.

Lymn, R. W., and Taylor, E. W. 1971. Mechanism of adenosine triphosphate hydrolysis by actomyosin. Biochemistry 10, 4617-4624.

Marshall, W. E., and Omachi, A. 1974. Measured and calculated NAD+-NADH ratios in human erythrocytes. Biochim Biophys Acta 354, 1-10.

Martin, P. G., Lasserre, F., Calleja, C., Van Es, A., Roulet, A., Concordet, D., Cantiello, M., Barnouin, R., Gauthier, B., and Pineau, T. 2005. Transcriptional modulations by RXR agonists are only partially subordinated to PPARalpha signaling and attest additional, organ-specific, molecular cross-talks. Gene Expr 12, 177-192.

Masuda, T., Dobson, G. P., and Veech, R. L. 1990. The Gibbs-Donnan near-equilibrium system of heart. J Biol Chem 265, 20321-20334.

Molloy, J. E., Burns, J. E., Kendrick-Jones, J., Tregear, R. T., and White, D. C. 1995. Movement and force produced by a single myosin head. Nature 378, 209-212. 
Monod, J., and Jacob, F. 1961. Teleonomic mechanisms in cellular metabolism, growth, and differentiation. Cold Spring Harb Symp Quant Biol 26, 389-401.

Muoio, D. M., MacLean, P. S., Lang, D. B., Li, S., Houmard, J. A., Way, J. M., Winegar, D. A., Corton, J. C., Dohm, G. L., and Kraus, W. E. (2002). Fatty acid homeostasis and induction of lipid regulatory genes in skeletal muscles of peroxisome proliferator-activated receptor (PPAR) alpha knock-out mice. Evidence for compensatory regulation by PPAR delta. J Biol Chem 277, 26089-26097.

Nicolis, G. 1977. Dissipative structures and biological order. Adv Biol Med Phys 16, 99-113. Prigogine, I. 1967. Introduction to thermodynamics of Irreversible Processes (New York, Wiley, J).

Prigogine, I. 1986. Life and physics. New perspectives. Cell Biophys 9, 217-224.

Rigoulet, M., Devin, A., Espie, P., Guerin, B., Fontaine, E., Piquet, M. A., Nogueira, V., and Leverve, X. 1998. Flux-force relationships in intact cells: a helpful tool for understanding the mechanism of oxidative phosphorylation alterations? Biochim Biophys Acta 1365, 117-124. Squire, J. M. 1981. The Structural Basis of Muscular Contraction (New York, Plenum Press). Stucki, J. W. 1980. The optimal efficiency and the economic degrees of coupling of oxidative phosphorylation. Eur J Biochem 109, 269-283.

Veech, R. L., Kashiwaya, Y., Gates, D. N., King, M. T., and Clarke, K. 2002. The energetics of ion distribution: the origin of the resting electric potential of cells. IUBMB Life 54, 241-252.

Veech, R. L., Lawson, J. W., Cornell, N. W., and Krebs, H. A. 1979. Cytosolic phosphorylation potential. J Biol Chem 254, 6538-6547.

Vidal, C., Dewel, G., and Borckmans, P. 1994. Au-delà de l'équilibre, Vol 46 (Paris). 
Wang, Y. X., Zhang, C. L., Yu, R. T., Cho, H. K., Nelson, M. C., Bayuga-Ocampo, C. R., Ham, J., Kang, H., and Evans, R. M. 2004. Regulation of muscle fiber type and running endurance by PPARdelta. PLoS Biol 2, e294.

Woledge, R. C., Curtin, A. N., and Homsher, E. 1985. Energetic Aspects of Muscle Contraction, Vol 41 (London, Academic Press).

Wu, P., Inskeep, K., Bowker-Kinley, M. M., Popov, K. M., and Harris, R. A. 1999. Mechanism responsible for inactivation of skeletal muscle pyruvate dehydrogenase complex in starvation and diabetes. Diabetes 48, 1593-1599. 


\section{Legends of figures}

Fig. 1. The ATP-ADP-Pi-actomyosin CB cycle. The CB cycle was subdivided into six different conformational states, with three detached states (D1, D2, and D3) and three attached states (A1, A2, and A3). Transition A3--> D1 was the ATP binding step; CB detachment occurred when ATP bound to the actin (A)-myosin (M) complex (AM) and the rate constant for detachment was $\mathrm{g}_{2}$; AM --> A + M. Transition D1--> D2 was the ATP hydrolysis; M + ATP -> M-ADP-Pi. Transition D2--> D3 was M-ADP-Pi --> M*-ADP-Pi. Transition D3--> A1was the attachment state: the myosin head (M*-ADP-Pi) bound to A and the rate constant for attachment was $\mathrm{f}_{1}$; M-ADP-Pi + A --> AM-ADP-Pi. Transition A1 -->A2 was the power stroke which is triggered by Pi release: AM-ADP-Pi --> AM-ADP + Pi. Transition A2 --> A3 was the release of the hydrolysis product ADP: AM-ADP --> AM + ADP.

Fig. 2. Thermodynamics ; (A) CB cycle velocity, WT versus KO: $p<0.05$; (B) affinity, WT vs KO: $\mathrm{p}<0.001$; (C) thermodynamic force, WT versus KO: $\mathrm{p}<0.001$; (D) entropy production, WT versus KO: $\mathrm{p}<0.01$. White column: WT $(\mathrm{N}=14)$; black column: $\mathrm{KO}(\mathrm{N}=15)$; Values are means \pm SEM.

Fig. 3. (A) linear regressions between thermodynamic force and CB cycle velocity $u$.

WT thermodynamic force $=3.14 \mathrm{E}-4+\left(2.72 \mathrm{E} 6^{*} \mathrm{v}\right) ; \mathrm{R}^{2}=0.64$

$\mathrm{KO}$ thermodynamic force $=-0,11+(6.00 \mathrm{E} 6 * \mathrm{v}) . \mathrm{R}^{2}=0.80$

(B) linear regressions between entropy production and peak efficiency Eff max.

WT entropy production $=4.98 \mathrm{E}-7-(1.13 \mathrm{E}-8 *$ Eff $\max ) ; \mathrm{R}^{2}=0.89$ 
$\mathrm{KO}$ entropy production $=1.66 \mathrm{E}-6-(4.09 \mathrm{E}-8 *$ Eff $\max ) ; \mathrm{R}^{2}=0.93$

(C) linear regressions between entropy production and unitary CB force $\pi$.

WT entropy production $=4.90 \mathrm{E}-7-(2,00 \mathrm{E}-7 * \pi 0) ; \mathrm{R}^{2}=0.89$

$\mathrm{KO}$ entropy production $=1.81 \mathrm{E}-6-(8.07 \mathrm{E}-7 * \pi 0) ; \mathrm{R}^{2}=0.93$

(D) linear regressions between entropy production and microcanonical partition function $\mathrm{z}$.

WT entropy production $=-1.11 \mathrm{E}-6+(1.05 \mathrm{E}-6 * \mathrm{z}) ; \mathrm{R}^{2}=0.90$

$\mathrm{KO}$ entropy production $=-1.33 \mathrm{E}-6+(1.22 \mathrm{E}-6 * \mathrm{z}) ; \mathrm{R}^{2}=0.90$

Fig. 4: Histological analysis of diaphragm muscle of KO and WT mice by light microscopy; (A):longitudinal section; Masson trichrome stain, OM x 100. WT mouse diaphragm was histologically normal; (B) longitudinal section; HES stain OM x 80. Diaphragm muscle from KO mice showed waxy degeneration indicating coagulation necrosis. Accumulation of clear watery vacuoles of varying size in the cytoplasm of the muscle (arrows) led to vacuolar degeneration swelling of part of the muscle fiber; (C) longitudinal section; Masson trichrome stain, OM x 80. KO mouse diaphragm showed numerous contraction bands (arrows); (D) longitudinal section; Masson trichrome stain, OM x 100. KO mouse diaphragm showed granular degeneration (black arrows) and cellular necrosis (white arrow). The granules were scattered irregularly throughout the fiber.

Fig. 5 (A) and (B). MHC electrophoresis: Mouse diaphragm was composed of 4 MHC isoforms. In WT, fast fiber type $2 \mathrm{X}$ predominated and represented about $60 \%$ of total MHC, whereas slow fiber type I represented only about $10 \%$. No differences in MHC isoform pattern were observed between WT and KO; (C) RT-PCR: mRNA expression of PPAR isotypes: no 
significant differences in PPAR $\delta$ or PPAR $\gamma$ transcript expression were observed in WT and KO mouse diaphragm; 


\section{Table 1.}

\section{Muscle and CB Mechanical Parameters}

\begin{tabular}{|c|c|c|c|}
\hline Parameters & WT & $\mathrm{KO}$ & $\mathrm{P}$ \\
\hline $\operatorname{Vmax}\left(\mathrm{L}_{0} \cdot \mathrm{s}^{-1}\right)$ & $7.2 \pm 0.4$ & $5.0 \pm 0.2$ & \\
\hline Po $\left(\mathrm{mN} \cdot \mathrm{mm}^{-2}\right)$ & $148 \pm 4$ & $112 \pm 11$ & 0.01 \\
\hline $\mathrm{a}\left(\mathrm{mN} \cdot \mathrm{mm}^{-2}\right)$ & $20.9 \pm 1.8$ & & NS \\
\hline $\mathrm{b}\left(\mathrm{L}_{0} \cdot \mathrm{s}^{-1}\right)$ & $1.0 \pm 0.1$ & $1.2 \pm 0.1$ & 0.03 \\
\hline$\pi 0(\mathrm{pN})$ & $2.4 \pm 0.1$ & $2.1 \pm 0.1$ & 0.001 \\
\hline $\mathrm{N}\left(10^{10}\right)$ & $6.3 \pm 0.2$ & $5.2 \pm 0.5$ & 0.05 \\
\hline Effmax $(\%)$ & $42 \pm 1$ & $39 \pm 1$ & 0.001 \\
\hline $\mathrm{f}_{1}\left(\mathrm{~s}^{-1}\right)$ & $294 \pm 23$ & $367 \pm 22$ & NS \\
\hline$g_{1}\left(s^{-1}\right)$ & $43 \pm 6$ & $94 \pm 11$ & 0.05 \\
\hline$g_{2}\left(s^{-1}\right)$ & $2864 \pm 177$ & $2010 \pm 94$ & 0.001 \\
\hline
\end{tabular}

Vmax: maximum unloaded shortening velocity; Po: total tension ; -a and -b: asymptotes of the hyperbolic force-velocity relationship; $\pi_{0}$ : unitary $\mathrm{CB}$ force; $\mathrm{N}$ is the $\mathrm{CB}$ number $/ \mathrm{mm}^{2}$; 
Effmax is the maximum muscle efficiency $(\%) ; \mathrm{f}_{1}$ is the peak value of the rate constant for $\mathrm{CB}$ attachment; $g_{1}$ and $g_{2}$ are the peak values of the rate constants for CB detachment. Data are mean values $\pm \mathrm{SE}$ 


\section{Table 2.}

\section{Statistical Mechanics}

$\begin{array}{lccc}\text { Parameters } & \text { WT } & \text { KO } & \text { P } \\ \text { z } & 1.08 \pm 0.01 & 1.16 \pm 0.02 & 0.001 \\ \ln \mathrm{Z} .\left(10^{9}\right) & 5.0 \pm 0.4 & 7.0 \pm 0.6 & 0.01 \\ \ln \Xi .\left(10^{9}\right) & 3.6 \pm 0.1 & 4.0 \pm 0.4 & 0.001 \\ \text { Smol: }\left(\mathrm{J} \mathrm{.K}^{-1} \cdot \mathrm{mol}^{-1}\right) & 2.93 \pm 0.11 & \\ \text { Emol: }\left(\mathrm{J} \mathrm{mol}^{-1}\right) & 682 \pm 24 & 9.47 \pm 0.24 & 0.001 \\ & & 975 \pm 40 & 0.001\end{array}$

Z: molecular partition function; Z: canonical partition function; $\Xi$ : grand canonical partition function; Smol: molar statistical entropy; Emol: molar internal energy. Data are mean values \pm SE. 


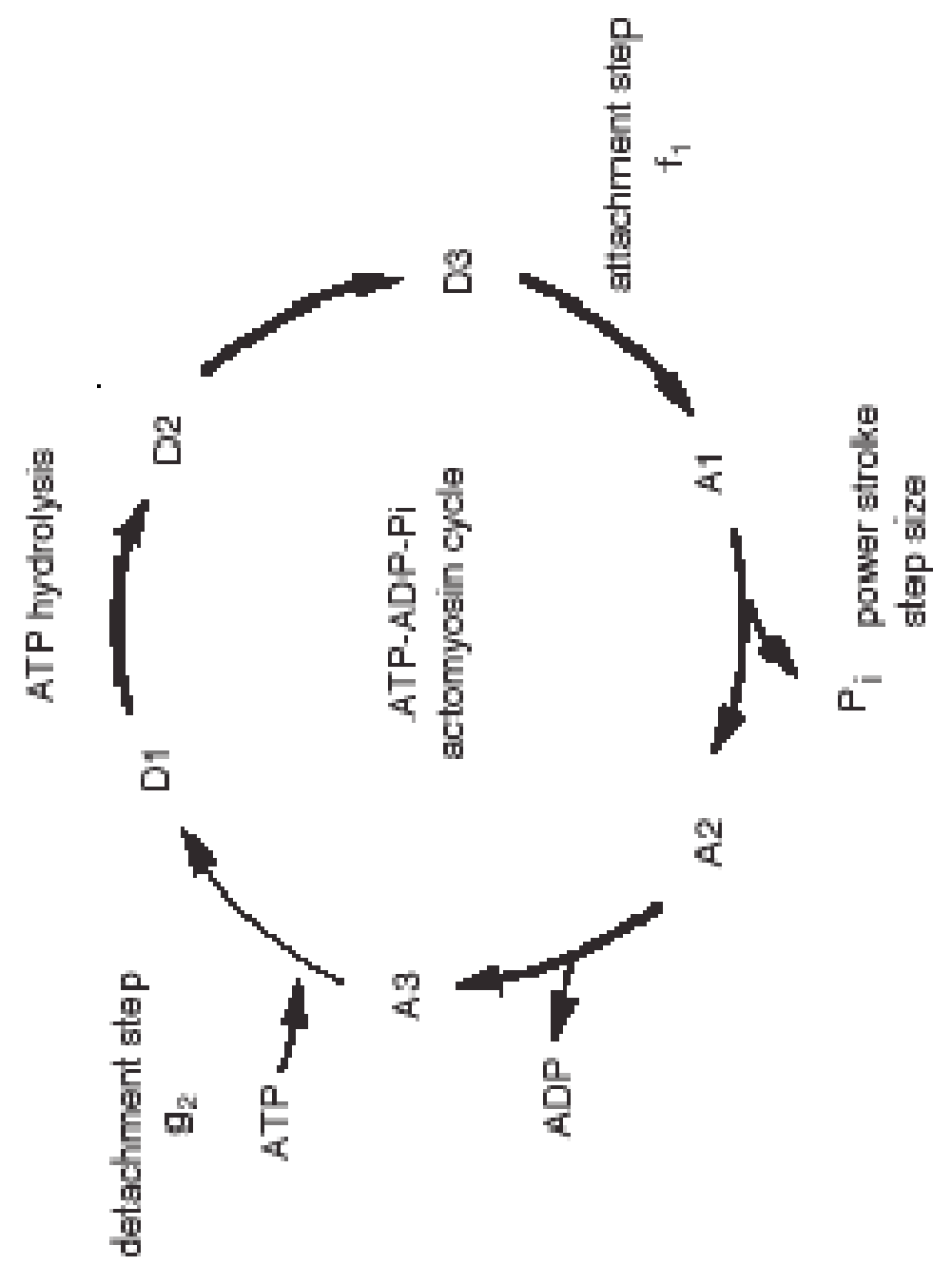



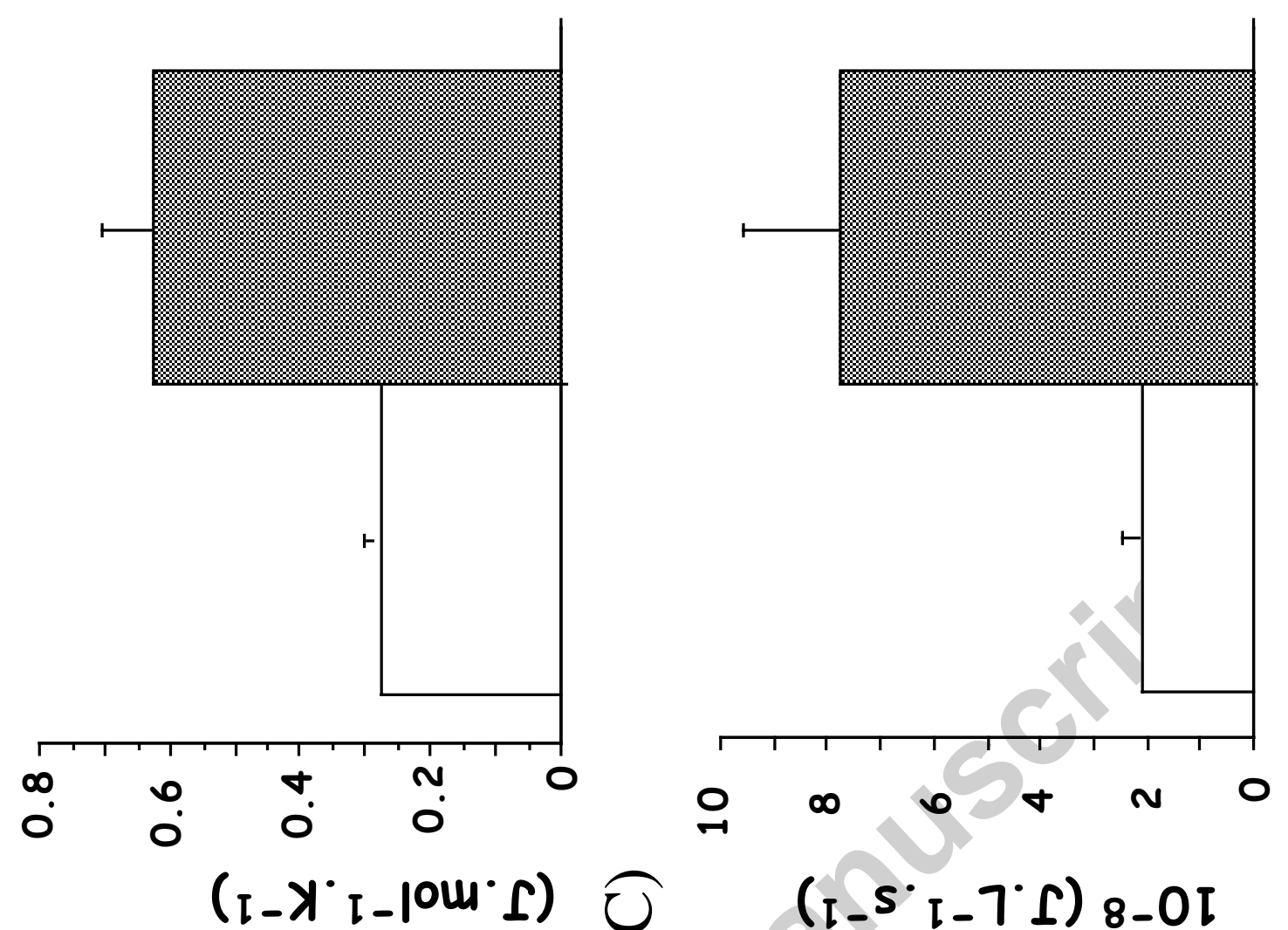

$$
\left(\tau-X^{\circ} \tau-\operatorname{lom}^{\circ} \tau\right)
$$

$\left(I-S_{2} I-T_{P} L\right)_{8-0 I}$

$\widehat{e}$

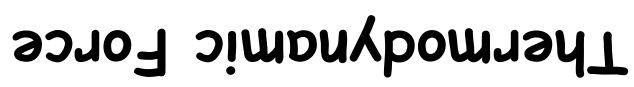

与 8

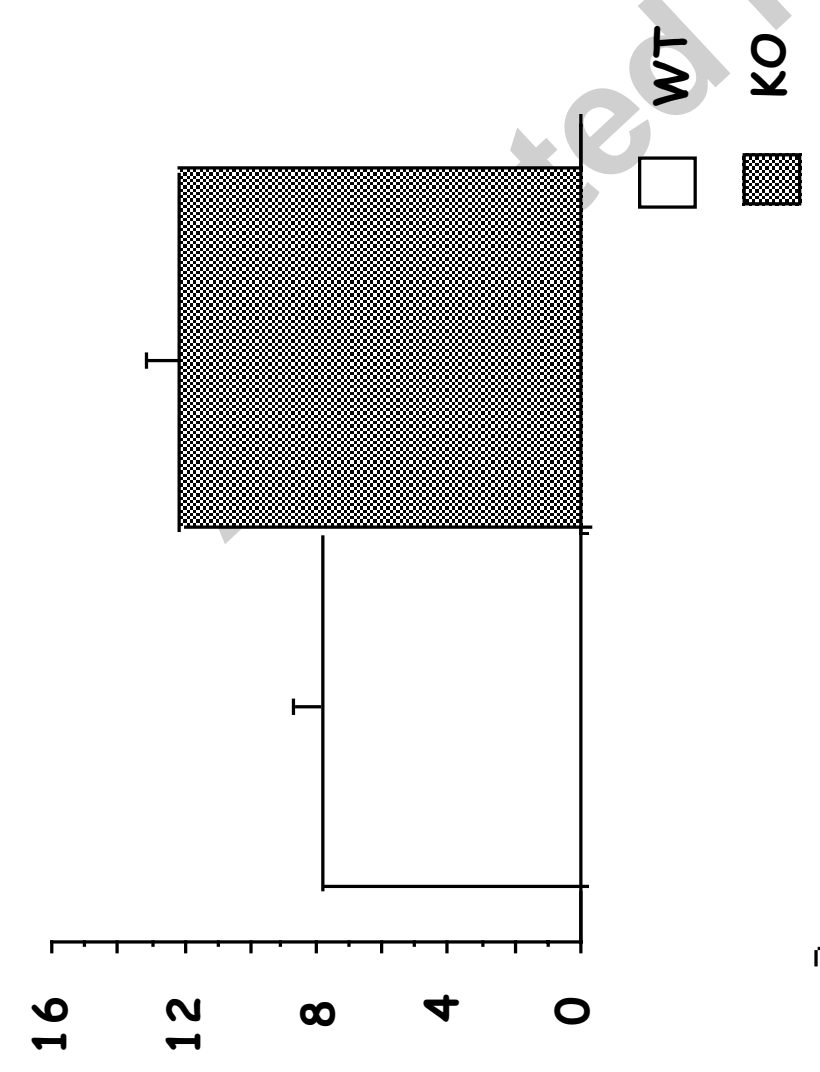

uo!tonpodd Kdoutu

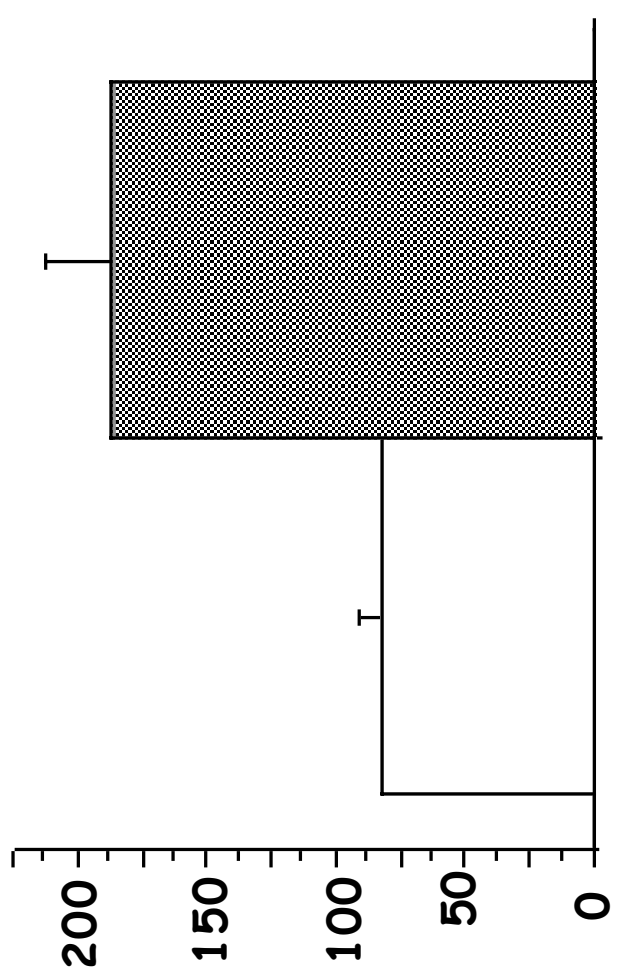

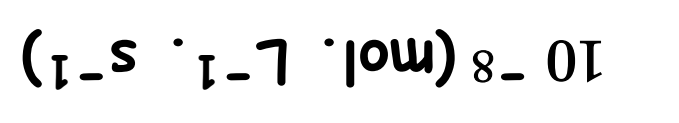

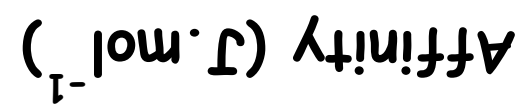



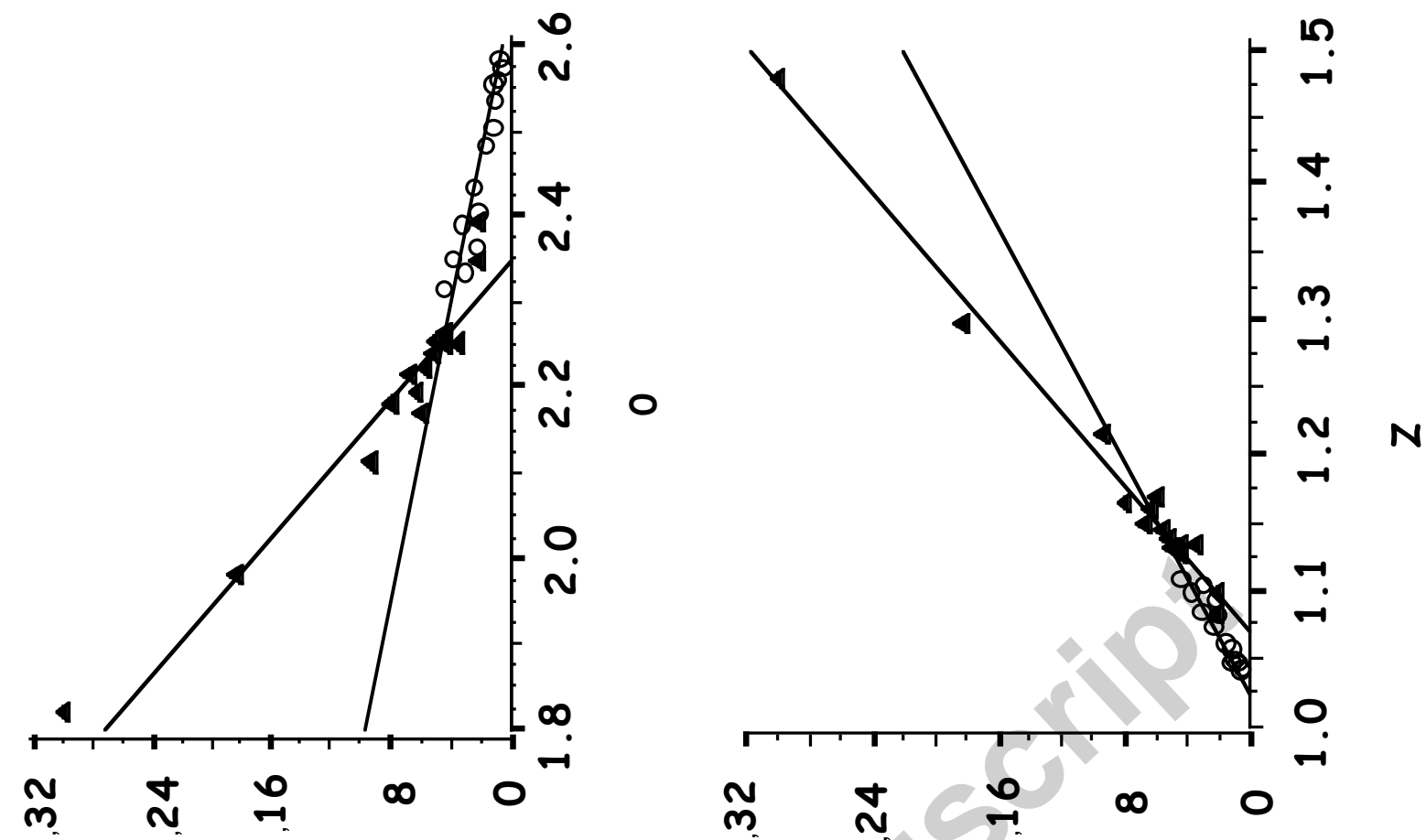

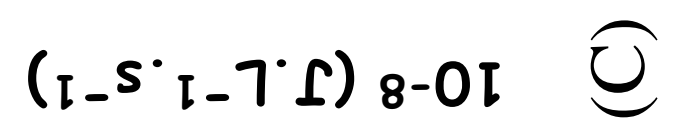
uo!tonpoud Rdoutuヨ

$\left(I-s^{\circ} I-7^{\circ} I\right) 8-0 I$

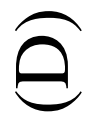

\section{uo!tonpoud Rdoutuヨ}
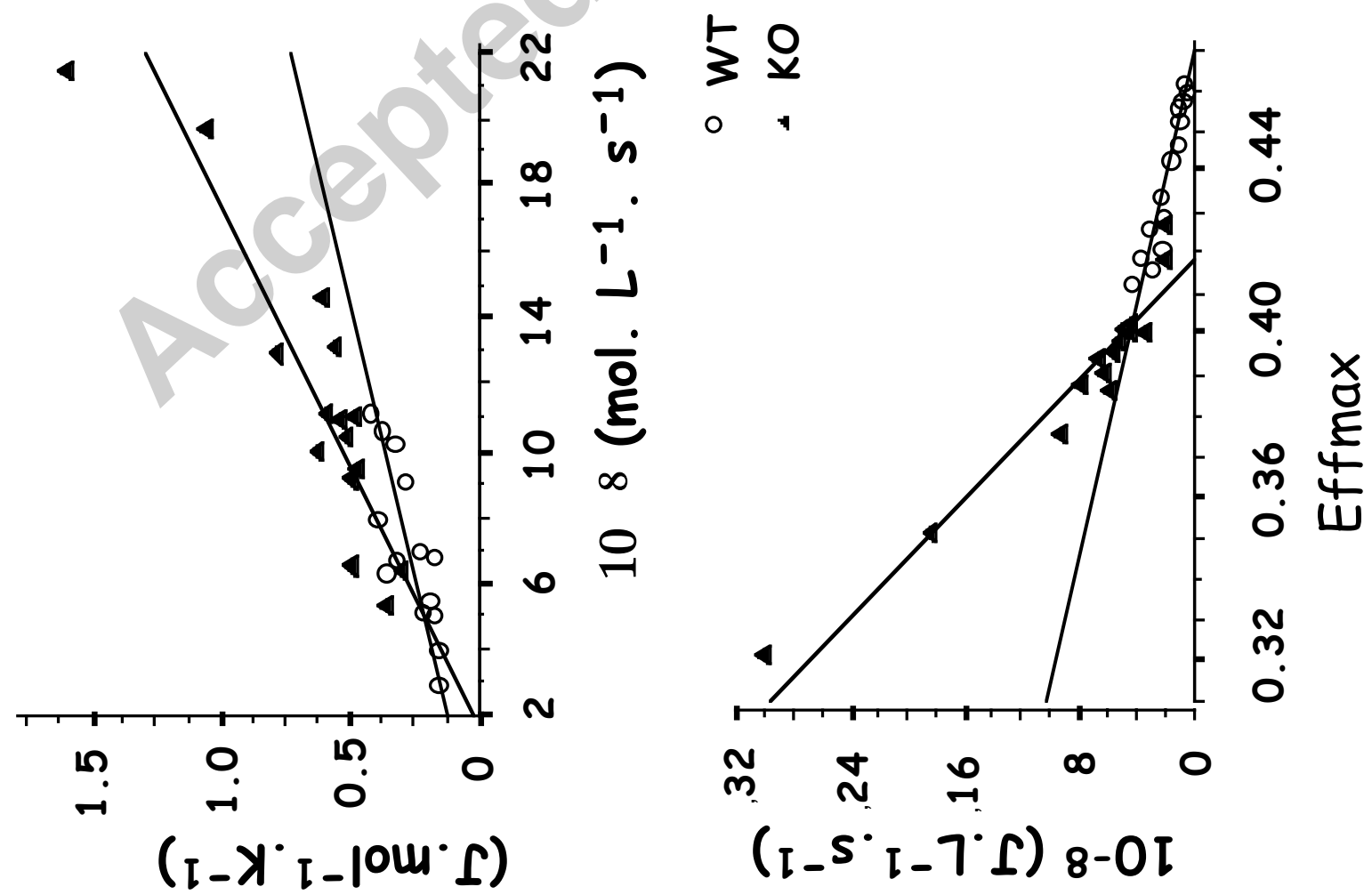

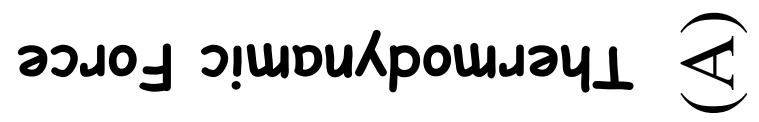

uo!tonpodd Kdodtu

$\widehat{\oplus}$ 


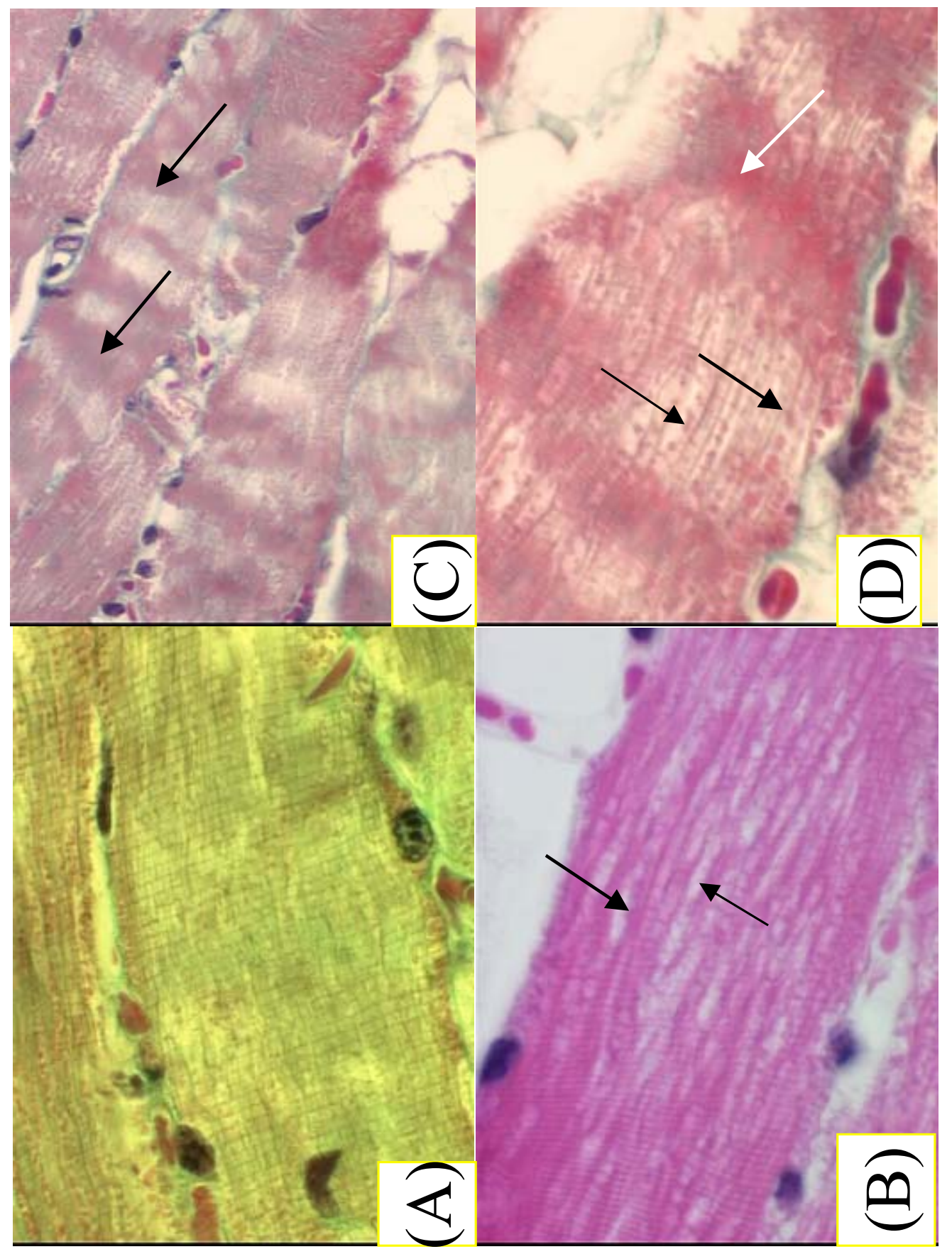



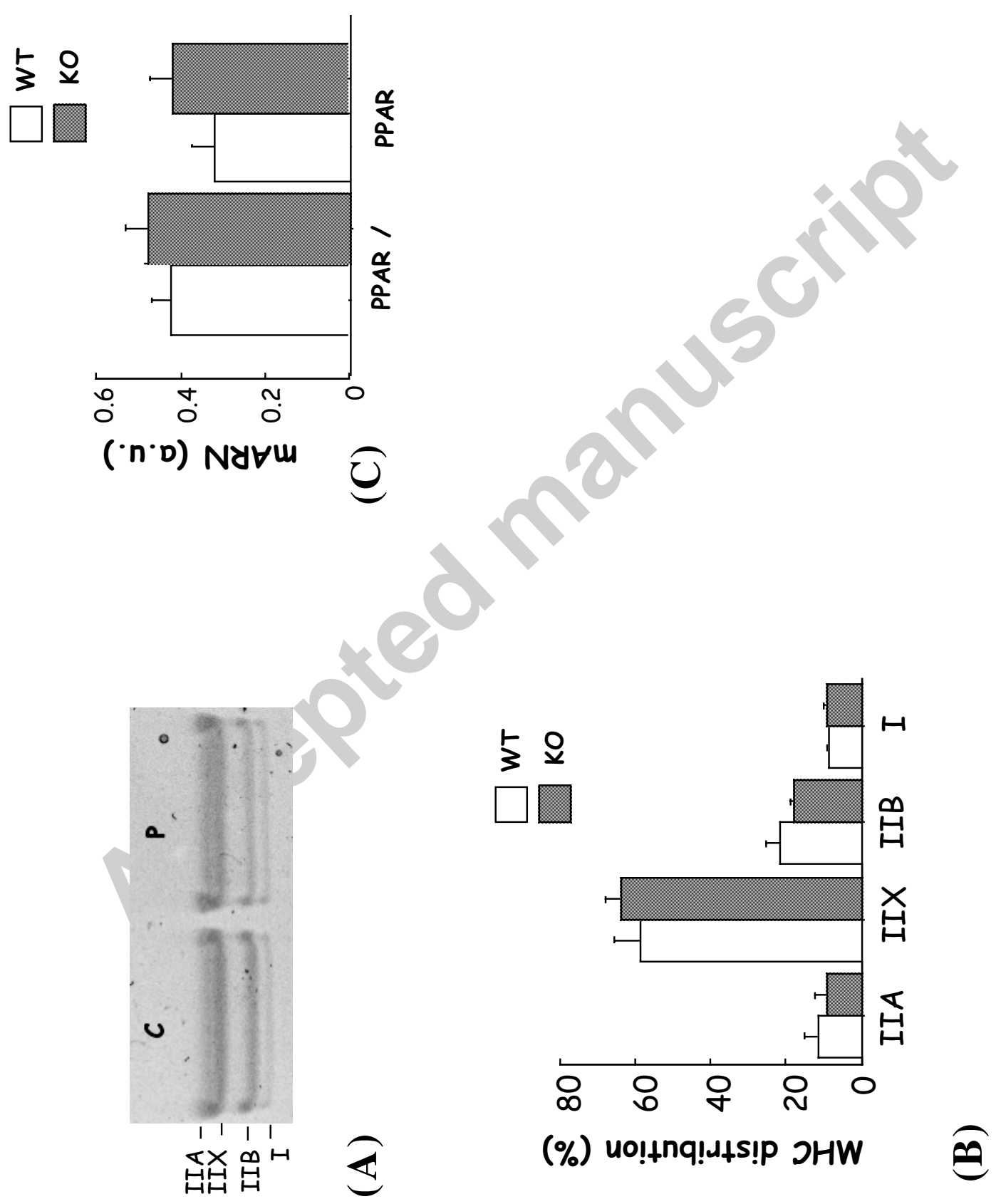